Article

\title{
Reduction of Friction and Soil Adhesion of Medium Carbon Steel via Hard Coating and Surface Texture
} \author{
and ShanJun Li \\ College of Engineering, Huazhong Agricultural University, Wuhan 430070, China; \\ wanghaobin@webmail.hzau.edu.cn (H.W.); zmhzau@webmail.hzau.edu.cn (M.Z.); \\ xugen0522@webmail.hzau.edu.cn (G.X.); Yu_JH@webmail.hzau.edu.cn (J.Y.); \\ Duxuan@webmail.hzau.edu.cn (X.D.); weimin@webmail.hzau.edu.cn (M.W.); \\ mengliang2006@mail.hzau.edu.cn (L.M.); shanjunlee@mail.hzau.edu.cn (S.L.) \\ * Correspondence: wanqiang0915@163.com
}

Haobin Wang, Qiang Wan *, Min Zhou, Gen Xu, Jiahuan Yu, Xuan Du, Min Wei, Liang Meng

Received: 28 April 2020; Accepted: 11 June 2020; Published: 12 June 2020

\begin{abstract}
Rapid development of mechanical cultivation demands satisfactory wear performance and lower soil adhesion on the soil-engaging components of terrain machinery. A thick $2 \mathrm{Cr} 13$ hard coating was used in conjunction with surface textures in this sector. The results showed that $2 \mathrm{Cr} 13$ coating and surface texture decreased the friction coefficient and wear rate enormously. The surface wettability of the coating was reduced by a dimpled-surface texture. The adhesion test suggested that dimples greatly decreased the adhesion force by decreasing the friction component and the decrement increased with the increase of dimple size. The adhesion force increased with the soil moisture and then decreased when exceeding the moisture content threshold.
\end{abstract}

Keywords: hard coating; surface texture; friction; soil adhesion

\section{Introduction}

Efficient, low cost mechanical cultivation is an important component of modern agriculture. However, it makes high demands on the soil-engaging component of terrain machinery because of soil abrasion and soil adhesion. Soil abrasion can greatly induce weight loss, and lead to the passivated corner of soil-engaging components. The formation of passivated corner would degrade the cultivation quality and affect the crop yields. Soil adhesion to the surface of the soil-engaging component has two adverse effects: the increase of draft resistance and the change of the contour. These two problems could lead to an increase in power consumption and the degradation of tillage effect. According to the published data, soil adhesion can increase plowing resistance by more than $30 \%$ [1], raise the energy consumption of tillage machinery by $30 \%-50 \%$ [2], and decrease productivity by $30 \%$ [3,4].

To solve the problem of soil abrasion, materials strengthening and surface strengthening methods, such as heat treatment and surface coating deposition, were widely explored to increase wear resistance. Increasing the hardness of surfaces has been proved to be an effective strategy to increase wear resistance in both agricultural machinery and industrial applications [5]. In the research of Hao J.J. et al., a plasma surfacing layer Fe-Cr-C-V was prepared on a $65 \mathrm{Mn}$ steel substrate and it was found that the weight loss as an indicator of wear resistance was significantly decreased by increasing the surface hardness with $65 \mathrm{Mn}$ hardened steel. Strengthening the coating on the surface of the soil-engaging component of agricultural machinery is highly efficient, flexible and convenient technology [6]. For the problem of soil adhesion, many methods such as the synthesis of the hydrophobic surface, tool vibration, and the creation of a flexible structure have been used to reduce their effects, regardless of geometric shape. Lu-Quan Ren, et al. developed a rough surface and flexible parts to remove soil 
accretion on the soil-engaging components, based on soil-burrowing animals [7]. However, the tool vibration would consume extra energy and the flexible surface was not suitable for the cultivation of compact soil. Thus, surface modification was considered as the proper candidate to reduce the adhesion. Current surface modification research on the soil-engaging component include surface strengthening and surface bionic engineering.

Traditional surface strengthening technologies such as carburizing, nitriding, and nitro-carburizing enhance wear resistance by introducing carbides or nitrides into the surface layer.

However, studies revealed good adhesion of these coatings with soil as compared with substrate [8]. Saeed studied the effect of nano-coating materials on the reduction of soil adhesion and external friction. Results showed that nano-coated plates exhibited a much lower friction coefficient and less adhesion than steel because of hydrophobic surfaces and roughness in the nanoscale [9]. Studies on the plastic-coated furrower also revealed lower draft force and soil adhesion due to its self-scouring ability and low frictional characteristics [10]. The thickness of these coatings is less than $100 \mu \mathrm{m}$ which is too thin for the abrasive wear caused by the hard abrasiveness of soil. In addition, the relatively low adhesion to the substrate is another limited factor for application in soil. Li J.W. manufactured a bionic structure according to the membranous leaf sheath of the grass root and reduced adhesion was achieved due to its hydrophobicity and special surface texture. [11] Hong L.J. et al. proved that the earthworm surface features could reduce the adhered soil mass by $36.7 \%$ [12]. Surface texture is widely used in industry to prepare a hydrophobic surface [13], enhance lubrication [14-16], and reduce the friction coefficient [17-19]. Under the starved-lubrication condition of oil or water, these textures act as traps to provide secondary lubrication to reduce the wear [20-22]. Coatings are often used to change the wettability for bacterial adhesion and self-cleaning applications [23,24]. Therefore, a combination of coating deposition with surface texture is an effective way to enhance the wear resistance and reduce the adhesion [25].

As described above, the effects of surface strengthening and bionic engineering on wear behaviors of soil-engaging components are studied separately. However, the soil adhesion properties are less focused because of the lack of testing equipment [26]. In addition, the combination of surface strengthening and surface bionic engineering has not been explored in soil-engaging components, and it is expected to increase the wear resistance and decrease soil adhesion simultaneously.

In this paper, the thick 2Cr13 hard coating and dimple-shape surface bionic structure have been applied in 45 steel which is the most popular steel used in agricultural machinery because of its excellent comprehensive mechanical properties. The combination of surface coating strength and surface texture is expected to increase the wear resistance and decrease the soil adhesion of the soil-engaging components. The friction behavior and soil adhesion are explored to gain understanding of the mechanism of friction-reduction and adhesion-reduction of the surface texture.

\section{Experimental}

\subsection{Coating Preparation and Surface Texturing}

Commercial 45 steel, a commonly used medium carbon steel in soil-engaging components, was used as the substrate with a size of $40 \mathrm{~mm} \times 40 \mathrm{~mm} \times 6 \mathrm{~mm}$ cut by electrical discharge machining. The composition of the substrate is listed as below, C: $0.42 \% \sim 0.50 \%$, Si: $0.17 \% \sim 0.37 \%$, Mn: $0.50 \% \sim 0.80 \%$, $\mathrm{P}: \leq 0.035 \%, \mathrm{~S}: \leq 0.035 \%, \mathrm{Cr}: \leq 0.25 \%, \mathrm{Ni}: \leq 0.30 \%, \mathrm{Cu}: \leq 0.25 \%$. Then, the surface of the substrate was ground and polished to a mirror-like surface to enhance the adhesion between coating and substrate. The $2 \mathrm{Cr} 13$ coatings were deposited by electric spark with fixed pulse time of $50 \mathrm{~ms}$ and fixed current of $50 \mathrm{~A}$, using D517 welding wires with a diameter of $1.6 \mathrm{~mm}$. The chemical compositions of D517 mainly consisted of $\mathrm{Fe}, \mathrm{Cr} \sim 10 \%-16 \%$, and $\mathrm{C} \sim 0.25 \%$. The high $\mathrm{Cr}$ content is expected to enhance the hardness by forming high density chromium carbides and to provide excellent corrosion resistance against the moisture corrosion of the soil. During the deposition process, argon gas was used to protect the coatings from oxidation with a flux of $10 \mathrm{~L} / \mathrm{min}$. After the deposition, samples were grounded to a 
mirror-like surface with a thickness of $3 \mathrm{~mm}$ retained. Then, the laser texturing process was applied by using a $\mathrm{CO}_{2}$ pulsing laser. Due to the lack of reports on texture applied in soil environments, the geometry, size, and distribution of micro-dimples were selected based on previous research about friction-reduction applications [14]. Various scan rates for the laser process were selected to develop micro-dimple textures with different diameters. The detailed parameters of these dimples are presented in Table 1. The bare steel sample and the coated samples are named as S and SC, respectively. The textured coated samples are named as SCT1, SCT2, SCT3, SCT4 corresponding to the dimple diameters of 100, 200, 300, $400 \mu \mathrm{m}$, respectively. The dimple area ratios of SCT1, SCT2, SCT3, SCT4, are $2.04 \%$, $8.28 \%, 18.65 \%, 33.15 \%$, respectively. The textured surface and dimples of SCT3 were revealed by optical microscopy and the scanning white light interferometry profiler (Bruker Contour GT-K), as shown in Figure 1a,c. The distance between two dimples is about $600 \mu \mathrm{m}$.

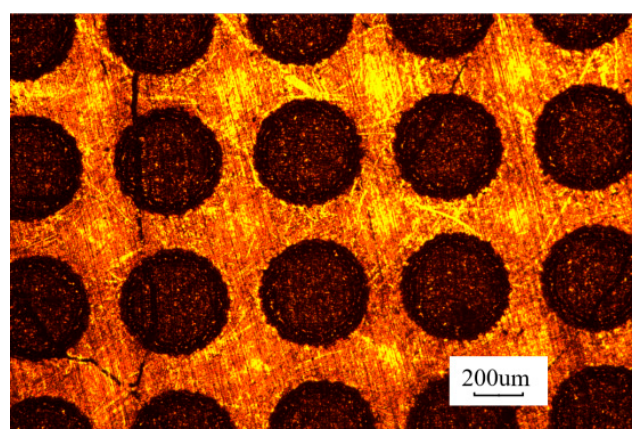

(a)

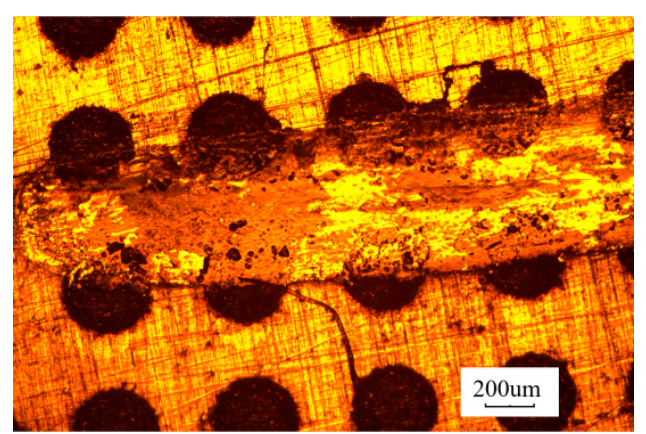

(b)

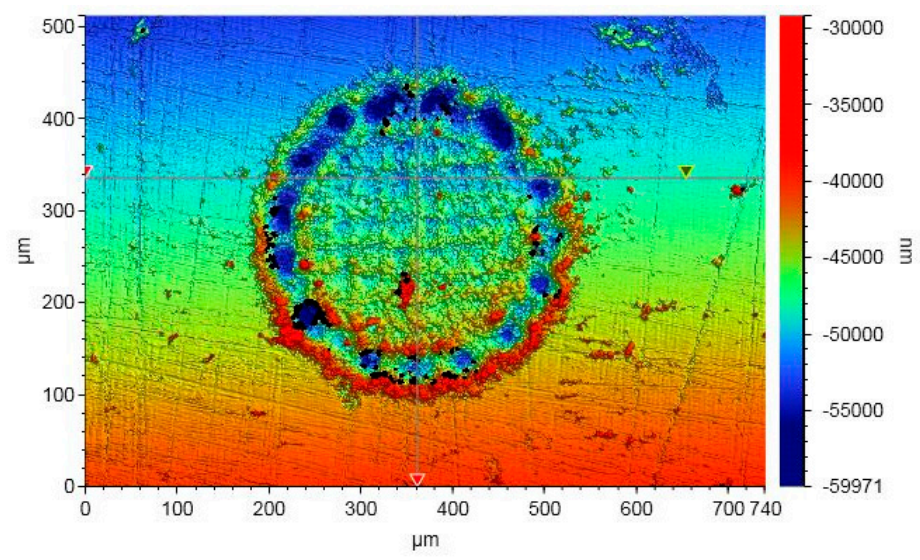

(c)

Figure 1. Morphologies of the textured surface with $300 \mu \mathrm{m}$ dimples: (a) before friction, (b) after friction, (c) profile of a dimple.

Table 1. Details of dimples in the coated steel.

\begin{tabular}{ccccc}
\hline Samples & Diameter $(\mu \mathrm{m})$ & Distance $(\mu \mathrm{m})$ & Depth $(\mu \mathrm{m})$ & Dimple Area Ratio $(\%)$ \\
\hline SCT1 & 100 & 600 & 400 & 2.04 \\
SCT2 & 200 & 600 & 400 & 8.28 \\
SCT3 & 300 & 600 & 400 & 18.65 \\
SCT4 & 400 & 600 & 400 & 33.15 \\
\hline
\end{tabular}




\subsection{Microstructure Characteristic and Hardness Test of the Coating}

The microstructure of $2 \mathrm{Cr} 13$ coating was evaluated by optical microscopy (OM) and ZEISS SIGMA field emission scanning electron microscope (FE-SEM). The chemical compositions of the different microstructures were detected by an energy dispersive spectrometer (EDS, EDAX genesis 7000 EDS system, Philadelphia, PA, USA). The cross section micro-hardness of the coated sample was measured by the hardness tester (HUA YIN, HV1000B, Lanzhou, China) from the coating to the substrate. The load of the micro-hardness test is $0.981 \mathrm{~N}$ with a holding time of $15 \mathrm{~s}$. The hardness data was tested every $0.2 \mathrm{~mm}$ and each point was measured several times to get the average value.

\subsection{Friction Test}

The friction coefficients were evaluated on the ball-on-disk tester (Rtec MFT-5000) at room temperature and under atmospheric pressure. $\mathrm{Si}_{3} \mathrm{~N}_{4}$ balls with a diameter of $6 \mathrm{~mm}$ were chosen as mated materials to simulate the friction of quartz sand, which is the main hard particle in soil. The reciprocating sliding test was carried out with a load of $150 \mathrm{~N}$ for $15 \mathrm{~min}$. The frequency was $5 \mathrm{~Hz}$ and the sliding distance was $5 \mathrm{~mm}$. The applied load of $150 \mathrm{~N}$ was selected to produce a contact pressure of nearly $2 \mathrm{MPa}$ which is close to the soil compactness of argillite horizon. The paths of the ball were selected to cover these dimples (shown in Figure 1b) to obtain the reduction effects of dimples on friction coefficient. Each tested sample was weighed before and after the friction test to obtain the wear rate.

\subsection{Soil Adhesion Test}

As described in the introduction section, no uniform standard has been established for the soil adhesion test, leading to the lack of commercial equipment. Thus, the soil adhesion test was conducted by self-made equipment in this research. It is worth nothing that the accuracy of the test data in this research has been verified by testing each sample in two modes: the single side adhesion test and total buried resistance test. The single side adhesion test was carried out in a soil friction coefficient meter (Xiamen Yishite Instruments co., Ltd. ST-MXZ-1, Xiamen, China). Under the single side adhesion test, the tested side contacted to the soil reservoir and moved with a constant velocity. The friction forces between the tested side of the metal sample and the soil in the contact area were recorded. The total buried resistance test was carried out in a self-made adhesion test system. The schematic of the equipment is shown in Figure 2. The soil bin was fixed at the end of the equipment with a slider inside. The slider was connected with an s-shaped precise load cell which could obtain the moving resistance. The motion of the sample was driven by a step motor. The sample was held at the end of the slider. A displacement sensor was fitted next to the slider to get the location of the slider during the test. Recorded motion resistance contained the adhesion of both sides and the force of breaking the ground induced by the thickness of the sample. The bare steel sample with the same size was also tested as a reference. The obtained adhesion forces of all coated samples were calculated by a deduction of the half value of the bare steel sample to get the adhesion force of the coated side. Even though the calculated data was higher than the real adhesion force with a fixed force of breaking ground involved, the variation trends of all samples in different moisture should be reliable. The soil for the adhesion test was taken from a citrus orchard in Huazhong Agricultural University located in central China. The moisture content was calculated by the weight loss ratio of the soil before and after drying which was conducted in an electric furnace at 107 degrees Celsius for $8 \mathrm{~h}$. 


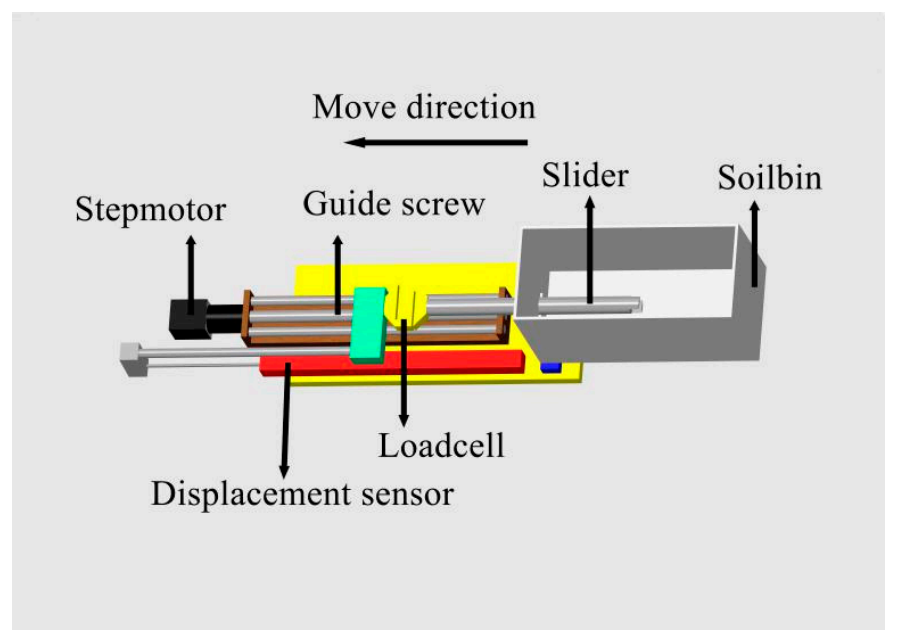

Figure 2. Schematic diagram of the equipment for the total buried resistance test.

\subsection{Wettability Test}

To explain the relationship between the change in adhesion force and the contact angle of water, the contact angles of the water on six samples were measured several times to get average values on the OCA25 data physics equipment. After the droplets were dropped on the surface under test with a handheld pipette, the moving sample table initially adjusted the droplets on the sample surface to the center of the optical system field of view, and after further focusing on the droplets, the average of the multiple sets of values measured by each sample was taken. Comparing six sets of data, the relationship between changes in the contact angle of water and changes in adhesion force was analyzed. We used a high-resolution camera to capture the images of liquid droplets, from which the contact angle can be calculated via the axisymmetric drop shape analysis (ADSA) method [27].

\section{Results and Discussion}

\subsection{Microstructure of 2Cr13 Coating}

Figure 3 shows the microstructure of the deposited $2 \mathrm{Cr} 13$ coating. From the figures, no defects such as cracks and voids were observed, which indicated that the coatings were well-formed and electro-spark deposition was suitable to strengthen the surface in the soil-engaging component of the agricultural machine. Figure 3 a shows that the coating was a typical dendritic structure composed of eutectic ledeburite and primary cementite. To further identify the microstructure of the coating and the chemical compositions of eutectic ledeburite and primary cementite, SEM and EDS were applied. Figure $3 \mathrm{~b}$ shows that the primary cementite was about $4 \mu \mathrm{m}$. The compositions of eutectic ledeburite (point 9,10 ) and primary cementite (point 8,11 ) are listed in Table 2. The coating was composed of $C$, $\mathrm{O}, \mathrm{Si}, \mathrm{Cr}, \mathrm{Fe}, \mathrm{Cu}$. The detected content of $\mathrm{C}$ was imprecise because of the limitation of EDS in detecting small number atoms. The small amount of $\mathrm{O}$ and $\mathrm{Cu}$ was from the oxidation of the coating and the welding electrode during preparation even under the protection of argon gas, respectively. The eutectic ledeburite phase also possessed a higher content of $\mathrm{Fe}$ and $\mathrm{Cr}$ than the primary carbides. The high content of $\mathrm{Cr}$ (over 20 at. \%) was expected to form chromium carbides to enhance the hardness. 


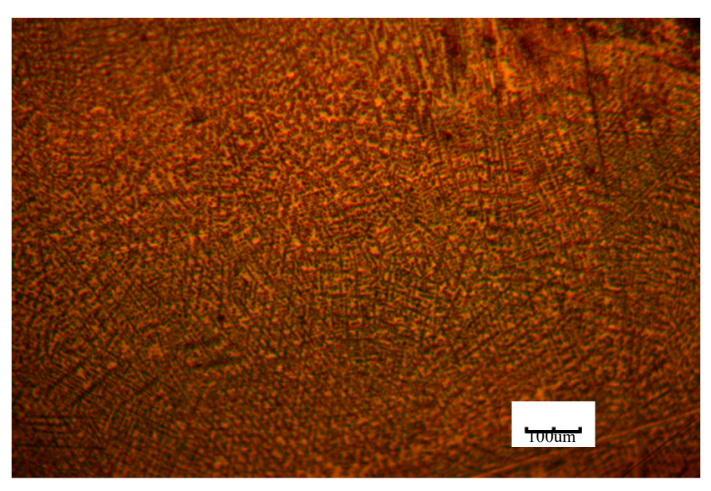

(a)

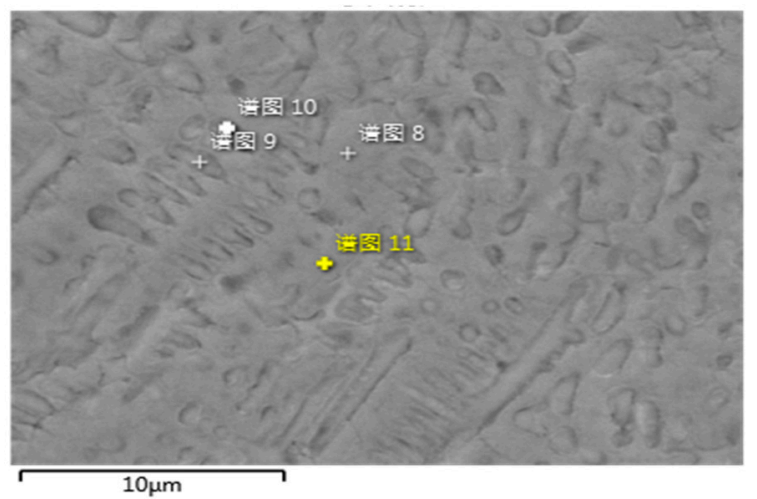

(b)

Figure 3. Microstructure of $2 \mathrm{Cr} 13$ coating: (a) observed by OM, (b) observed by SEM.

Table 2. Chemical compositions of different phases in coatings.

\begin{tabular}{ccccccc}
\hline Elements (at. \%) & Fe & Cr & C & Si & Cu & O \\
\hline Eutectic ledeburite & 53.33 & 20.29 & 21.73 & 0.65 & - & 4.00 \\
\hline Primary cementite & 46.98 & 16.66 & 30.11 & 0.75 & 0.59 & 4.91 \\
\hline
\end{tabular}

\subsection{Micro-Hardness of 2 Cr13 Coating}

Hardness is an important indicator of the wear resistance and energy absorption under impact load. For this reason, the hardness of the coating and substrate was measured from the top surface of the coating to the bottom substrate (as shown in Figure 4). The hardness quickly decreased from 1016 $\mathrm{HV}$ to $235 \mathrm{HV}$. The observed high hardness over $1000 \mathrm{HV}$ in the top surface was related to the fine crystallinity formed by the fast cooling rate. The coating presented a high hardness over $700 \mathrm{HV}$ while the substrate presented a hardness under $235 \mathrm{HV}$, which suggested that the hardness nearly increased by three times. According to the calculated formula of wear volume under debris wear [28]: $V=\frac{K N L}{H}$, $V$ is the wear volume and $H$ is the hardness, the wear volume is inversely related to the hardness. It could be concluded that $2 \mathrm{Cr} 13$ coating greatly enhanced the wear resistance of the steel-made soil-engaging component by decreasing the wear volume to a third. The decrease in hardness in a cross-sectional direction was related to the heat effect. For the coating, the top surface possessed the largest cooling rate and formed fine grains which resulted in high hardness. As the distance to the top surface increased, the cooling rate decreased and led to coarse grains. Thus, the hardness of the coating decreased. However, the heat effect on the hardness in the substrate was different. The conducted heat from the coating to the near substrate led to the transformation of the hard phase which greatly increased the hardness of the substrate. These heat-affected zones of the substrate with higher hardness also could decrease the wear rate of the inner substrate. 


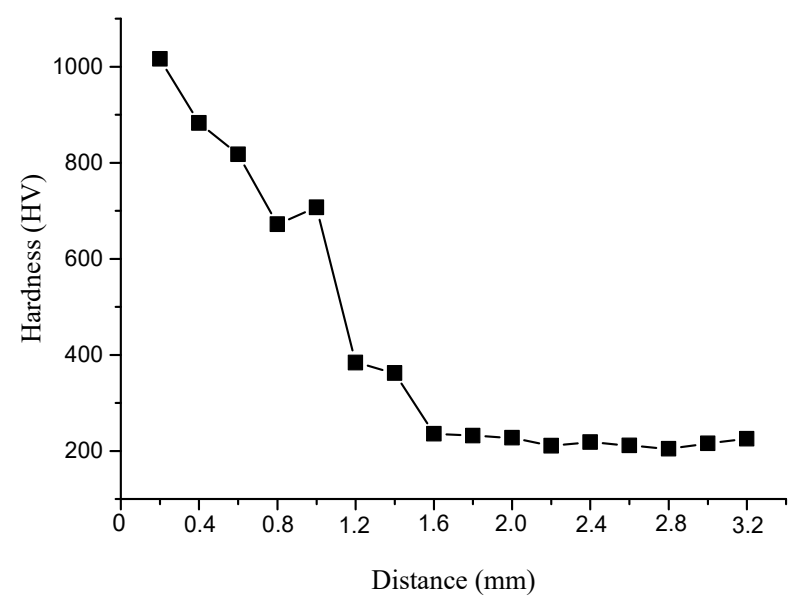

Figure 4. The cross-sectional hardness of the coating as a function with the distance to the top surface of the coating.

\subsection{Friction Behavior}

The friction coefficient and weight loss of all coated samples are shown in Figure 5 and the substrate is also presented as a reference. From the wear coefficient curves, the friction curves of all samples revealed a similar trend as the friction time increased. The coefficient of friction (COF) firstly increases with time, then gradually decreases to a stable value. The increase in the friction coefficient is due to the debris generated by the wear and the increased contact area which increases the scratch resistance during the sliding of the ball [28]. When the contacted area reaches a dynamic balance, the COF becomes stable. All coated samples revealed a lower friction coefficient as compared with the bare steel substrate which suggested better wear resistance of the coating under a large load. It also could be concluded that samples with dimple textures in the surface reveal lower COF under 0.5 while that of the coating without dimple textures was above 0.55 . The results suggested the micro-texture could reduce the friction coefficient which has also been reported in YT15 cemented carbides [29]. The reason is considered to be related to the reduction of the actual contact surface area in the friction process. The $\mathrm{COF}$ also varies with the size of the dimple texture. A coating with a dimple size of $100 \mu \mathrm{m}$ presents the lowest COF while that of other samples with 200,300, $400 \mu \mathrm{m}$ are almost the same. It has been reported that the dimple diameter and surface density have a great influence on the friction coefficient. The literature has suggested a reasonable dimple diameter can reduce the friction coefficient to the greatest extent: when the dimple diameter is too small, the dimple cannot capture the generated grinding to reduce the friction coefficient. Furthermore, larger dimples make the capture of the grinding a little later [30]. The weight loss of all samples during the friction test is listed in Figure 5b. The change in weight of all samples agreed well with the change of COF except for the sample with $300 \mu \mathrm{m}$ dimples. The weight loss of the sample with dimples not only related to the COF, but also correlated with the contact area during the test. The way to measure the wear amount is to weigh the sample and record the data before doing the friction experiment. After the friction experiment is finished, the sample is cleaned with an ultrasonic wave, and the data is weighed and recorded again. The sample with $300 \mu \mathrm{m}$ dimples presented the lower COF but possessed a larger contact area compared with the sample with $400 \mu \mathrm{m}$. Thus, a slight decrease in weight loss could be observed as the size of dimples increased from 300 to 400. Based on the above friction tests, the larger the size of the dimples (with a size lower than $400 \mu \mathrm{m}$ ), the lower the weight loss obtained. However, soil adhesion also should be considered in the application of surface engineering in soil-engaging components, besides the wear behavior. 


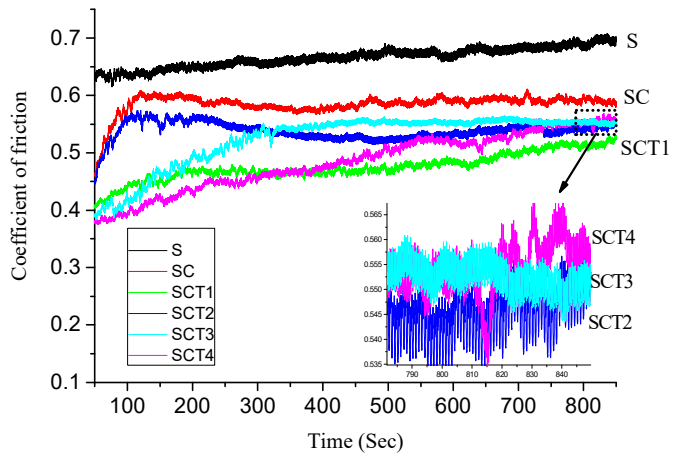

(a)

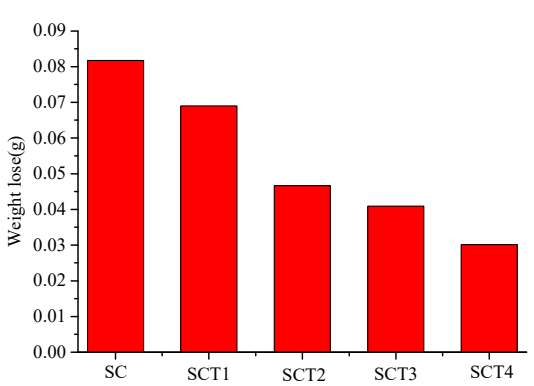

(b)

Figure 5. (a) Results of friction test: (a) COF, (b) weight loss of all samples.

\subsection{Adhesion Resistance}

The power consumption during the cultivation of soil is determined by the power needed for the breaking of soil and the power to overcome soil adhesion. The power for breaking soil is decided by the soil condition and the shape of the cutting edge, not the surface condition. Soil adhesion, which is greatly affected by the surface condition of the soil-engaging component, has been tested in this paper. The soil friction force between the functioning surface and the soil (FFSS) and the soil adhesion force (SAF) have been studied under different moisture contents by the commercial soil friction meter and the self-made adhesion test system, respectively. The results are shown in Figure 6a,b.

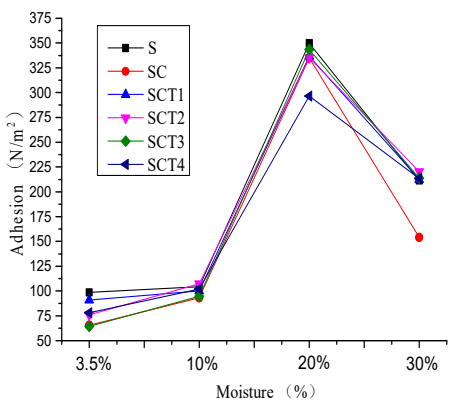

(a)

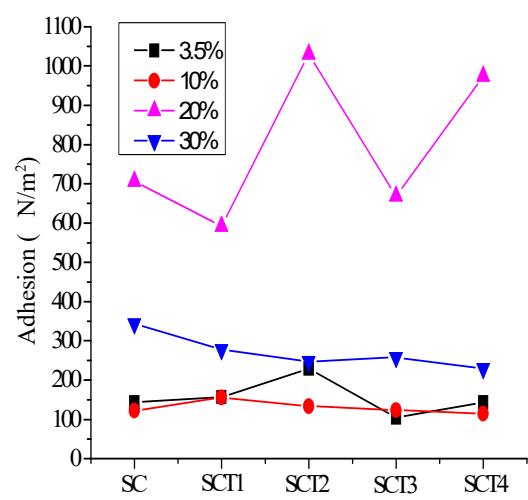

(b)

Figure 6. Adhesion test results under different moistures: (a) friction force between functioning surface and the soil, (b) soil adhesion.

According to the results, the soil friction force of the coated samples was lower than the uncoated sample under different moisture contents. Moreover, dimples on the coated surface could further decrease the FFSS. Thus, it could be concluded that the application of $2 \mathrm{Cr} 13$ coating and surface texture on the surface of the substrate of 45 steel is an effective method to decrease power consumption. The effects of moisture content on the FFSS of these coatings is revealed in Figure 6a. The FFSS of all samples firstly increased with the increase of moisture content and then decreased. The maximum FFSS was observed in $20 \%$ moisture content, which is about three times that of soil with a moisture content of $10 \%$. A similar soil adhesion threshold has also been reported by other researchers. Similar changes of tangential adhesion under different moisture contents also have been observed by other researchers [31]. The reason has been attributed to the increase of the adhesion of soil meniscus [32]. 
Figure $6 \mathrm{~b}$ presents the SAF of samples as a function of the size of the dimples. As the moisture content increased from $3.47 \%$ to $10 \%$, the value of SAF slightly increased. Further increases in moisture content led to a significant increase in SAF. Samples tested in soil with $20 \%$ moisture content revealed the largest SAF which was about 2.5 times the second largest SAF observed in soil with $30 \%$ moisture content. The changed trends of SAF with the moisture content agree well with those of FFSS, which proves the accuracy of the measured data.

The effects of dimple texture on the SAF varied for samples tested in different moisture contents. Samples tested under $3.47 \%, 10 \%$, and 30\% moisture content revealed a similar trend in SAF as a function with the dimple size. The SAF has been greatly decreased by the synthesized dimples and slightly decreased as the size of dimples increased from 100 to $400 \mu \mathrm{m}$. However, the effect of dimples on SAF for samples tested under a moisture content of $20 \%$ was different from that of samples tested under $3.47 \%, 10 \%$, and $30 \%$ moisture content. Under a moisture content of $20 \%$, samples with 200 and $400 \mu \mathrm{m}$ dimples showed higher SAF as compared with the coated sample without dimples, while samples with 100 and $300 \mu \mathrm{m}$ dimples showed relatively lower SAF. Therefore, it could be concluded that the dimpled texture could efficiently decrease the friction force between the soil and metal substrate, as well as the soil adhesion force. Furthermore, the decrement of FFSS and SAF was closely related to the moisture content of the soil. To illustrate the adhesion results, the contact angle measurement of the coated samples was carried out.

\subsection{Wettability Test}

Figure 7 presents the contact angles of water on the surface of the steel substrate, the coated sample, and the textured surface coatings. Compared with the coated substrate without surface texture, the coated samples with dimples exhibited larger contact angles above $90^{\circ}$, which suggested that the coating surface transformed from tiny hydrophilic into hydrophobic after the laser drilling treatment. The coating with surface texture even revealed more hydrophobic properties as compared with the bare steel. The wettability of a surface is mainly related to its chemical nature, and surface structures [33]. The preparation of dimples on the surface by laser treatment also caused the oxidation of the materials around the pores. These oxides are the nanoscale structure which is more efficient in repelling the water film $[34,35]$. The main contribution to the lower wettability was from these micropores which entrapped air to provide upward pressure under the gravity load of soil [36]. The molecular dynamic study of Lei Chen pointed out that the micro surface texture could enhance the hydrophobicity of the surface by decreasing the surface characteristic energy [35]. The enhanced effect on the hydrophobicity increased with the size of the nanostructured texture. Lower wettability was reported as being helpful in decreasing soil adhesion, which was responsible for the observed lower soil adhesion of coated samples with dimples.

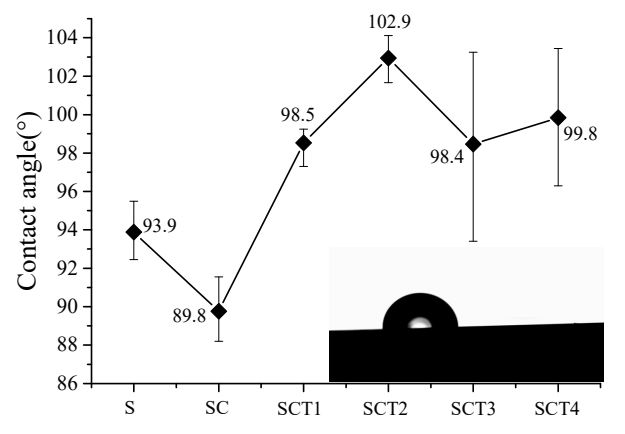

Figure 7. Contact angles of water on the surface of all samples.

\subsection{Influence Mechanism of Surface Texture on the Wear Behavior and Soil Adhesion}

Abrasive wear, caused by hard abrasiveness in soil, and soil adhesion are the main limitations for the soil-engaging component of the soil tillage equipment. To extend the life of the soil-touching 
part and decrease energy consumption, a surface texture of dimples with different sizes was applied to the original substrate. The wear test and soil adhesion test were carried out to study the effects of dimples. According to the wear test, the friction coefficient and weight loss of samples with dimples in the surface were decreased. The results suggested that the application of dimples to the surface of the soil-engaging component could be an effective method to reduce abrasive wear. The reason for the decrease of friction coefficient and weight loss could be related to the decrease of the actual contact area and the storage of debris by the dimples $[37,38]$. The size of the dimples in these samples was under $400 \mu \mathrm{m}$ which was smaller than the diameter of the ceramic friction ball. Thus, the actual contact area between the sample and ball could be greatly decreased and led to a decrease in the friction coefficient and a reduction in weight loss (an indicator of the wear rate) during the friction test. The larger the dimples, the smaller the friction coefficient and wear rate. Besides, the dimples could collect the debris produced by the friction process. According to tribology theory, debris has two effects on tribological behaviors [39]. First, the debris might collect in the wear track and hinder the motion of the friction pair, which leads to the increase of the friction coefficient. Second, this debris could be oxidized under the atmosphere when the temperature is increased by the friction heat. These hard oxides would lead to the additional abrasive wear. Thus, the storage of debris by these dimples could decrease the friction coefficient and the wear rate. The reduction effect increases with the size of dimples because more debris is captured. However, the size of a critical dimple also succeeded in reducing the COF and wear rate.

As revealed by the results of adhesion tests, the following conclusions could be drawn:

1. Adhesion increased with the soil moisture and then decreased when exceeding the moisture content threshold;

2. Coated samples with dimples revealed lower soil adhesion than samples without dimples;

3. The adhesion force decreased with the increase of the size of the dimples.

Based on the soil mechanics, the soil adhesion force $F_{q}$ could be described with the formula below [40]:

$$
F_{\mathrm{q}}=\mathrm{f}_{\mathrm{m}}^{\prime}\left(N_{\mathrm{m}}+S \sum N_{\mathrm{ni}}\right)+S \sum N_{\mathrm{nj}}+F_{\mathrm{f}}
$$

$f^{\prime}{ }_{m}$ is the proportional coefficient between normal force and tangential resistance, $N_{\mathrm{m}}$ is the gravity force of the covered soil covered on the sample, $\mathrm{S}$ is the contact area between soil and metal surface, $N_{\mathrm{ni}}$ is the normal adhesion, $N_{\mathrm{nj}}$ is the tangential adhesion, $F_{\mathrm{f}}$ is the viscous force between the water in the dimples and the soil and water mixed liquor film.

In this paper, the samples were cut into the same size to ensure the same value of $\mathrm{N}_{\mathrm{m}}$. The same test conditions for all samples also guaranteed the same $f^{\prime} \mathrm{m}$. The soil adhesion force of all samples could be affected by four factors, $S, N_{\mathrm{ni}}, N_{\mathrm{nj}}$, and $F_{\mathrm{f}}$. The tangential adhesion $N_{\mathrm{nj}}$, consisting of $N_{\mathrm{nn}}$, $N_{\mathrm{nm}}$, and $\tau_{\mathrm{n}}$, which corresponded to the water viscous force of a soil water liquor film, negative capillary pressure suction, and the meniscus adhesion force of wet soil. The water viscous force of soil and a water mixed liquor film were the source of the friction resistance. The negative capillary pressure suction and meniscus adhesion force of wet soil made the main contribution to the adhesion. It is important to note that the value of $N_{\mathrm{nn}}, N_{\mathrm{nm}}$, and $\tau_{\mathrm{n}}$ could be greatly affected by the moisture content in water [40]. Publications suggest that the water film area increases with the increase in moisture content and leads to a decrease in friction resistance because of the lubrication of water between the wet soil and the metal surface [41,42]. However, the increase of water in the soil could also result in an increase of the adhesion by enhanced negative capillary pressure suction and the meniscus adhesion force of wet soil. Hence, the soil adhesion continued to increase with the moisture content until the liquid moisture content limit was reached [40]. Under the liquid limit state, the soil possessed excellent plastic deformation ability to form an intact lubrication film and small friction resistance was obtained. Meanwhile, the liquid moisture content limit also brought the largest adhesion. With a further increase in moisture content, meniscus adhesion gradually disappeared and negative capillary pressure suction 
would diminish, which led to a decrease in soil adhesion. The variation of the adhesion with the moisture content could be related to the reason described above.

Among these four factors, $F_{\mathrm{f}}$ is closely related to the total area of dimples and relatively small as compared with the normal and tangential adhesion. Hence, the value of $S$, which is the proportional coefficient of the other three impact factors, could greatly affect the soil adhesion force. As Figure 8 illustrates, these dimples would be filled with soil and water mixed liquor because of the formation of negative cavity air pressure when the relative sliding happened between the wet soil and the textured surface [43].

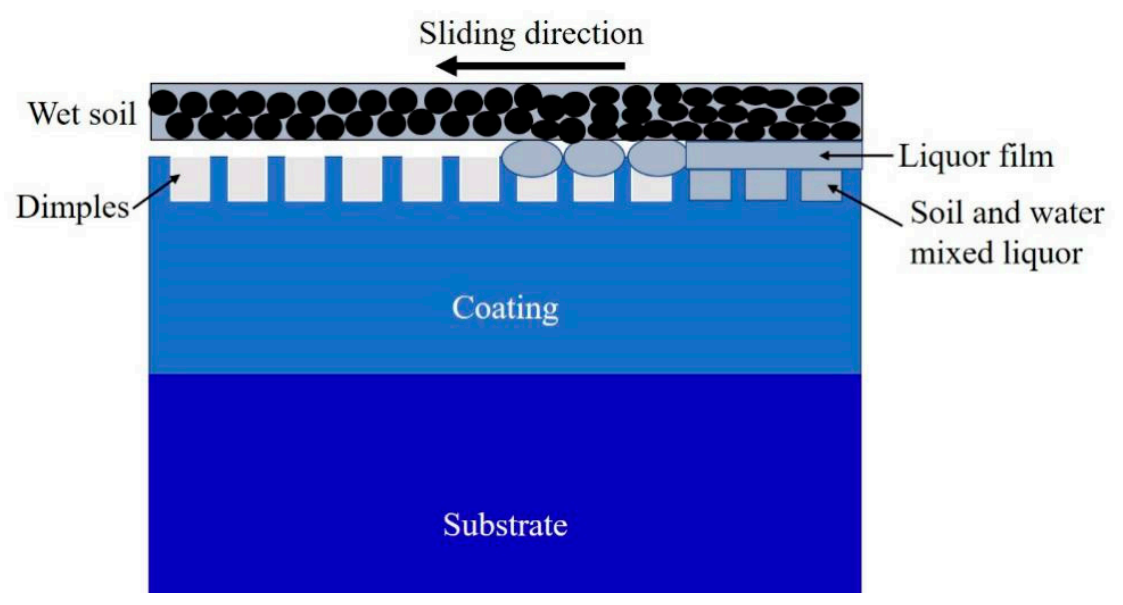

Figure 8. Schematic of dimples in reducing soil adhesion.

Thus, the original metal/soil friction interface converted into liquid/soil interface and resulted in a great decrease in friction force, even before the lubricating soil and water mixed liquor film formed in the textured surface. The existence of the micro-texture could greatly decrease the contribution of $\sum N_{\mathrm{ni}}$ and $\sum N_{\mathrm{nj}}$ to $F_{\mathrm{q}}$ and increase the value of $F_{\mathrm{f}}$, while the increase of $F_{\mathrm{f}}$ could be ignored as compared to the decrement. This is the reason for the decrease of $F_{\mathrm{q}}$ for samples tested under a moisture content of $3.47 \%, 10 \%$, and $30 \%$. As the diameter of dimples increased from 100 to $200,300,400 \mu \mathrm{m}$, the total area ratio of dimples increased from $2.04 \%$ to $8.28 \%, 18.65 \%, 33.15 \%$ which suggests that the decrement of the friction force component of soil adhesion continued to increase. On the basis of the above study, the surface texture could decrease the friction coefficient, wear rate, and soil adhesion. However, the effect of dimples on the integrity of materials should be taken into consideration. The larger dimple means fewer materials retained in the surface and decreasing the strength of the surface. The significant decrease in the strength would also accelerate the wear rate during the soil abrasive wear. Therefore, the size of the dimples should be designed based on the consideration of tribological behavior, soil adhesion, and surface strength together.

\section{Conclusions}

In this study, dimples with four different sizes and 2Cr13 hard coatings were applied in 45 steel. The friction test and adhesion test were investigated. The friction results suggest that $2 \mathrm{Cr} 13$ coated samples reveal a lower friction coefficient and wear rate than the steel, due to its higher hardness. The dimples in the coating further decrease the friction coefficient and wear rate by decreasing the actual contact area. Based on the adhesion test under different moisture contents, it is concluded that adhesion increases with the soil moisture and then decreases when exceeding the liquid moisture content limit which provides a soil and water mixed liquor film between the metal surface and soil as a lubricant. The adhesion force is greatly reduced by the application of dimples on the surface because of the lower wettability and the conversion of the original metal/soil friction interface into liquid/soil friction interface. The conversion decreases the friction component before a soil and water mixed 
liquor film forms. The decrement of soil adhesion force increases with the increase of the dimple size under different levels of moisture content except at the liquid limit. These results could be helpful for understanding the mechanism of soil adhesion. Achieving a lower friction coefficient and adhesion between soil and a surface textured coating on the steel shows a potential application in soil-engaging components to reduce soil adhesion. However, the wear rate and soil adhesion should be calculated in soil tillage experiments in further research to explore the above-mentioned application.

Author Contributions: Conceptualization, H.W. and Q.W.; Data curation, H.W., M.Z. and G.X.; Formal analysis, H.W.; Methodology, M.Z., J.Y., X.D. and Q.W.; Project administration, H.W.; Resources, M.W.; Software, H.W. and G.X.; Supervision, G.X., M.W., S.L., L.M. and Q.W.; Validation, H.W., J.Y., S.L. and Q.W.; Visualization, M.Z., L.M. and Q.W.; Writing - original draft, H.W., M.Z., G.X., J.Y. and X.D.; Writing - review \& editing, H.W. and Q.W. All authors have read and agreed to the published version of the manuscript.

Funding: This work was supported by the National Natural Science Foundation of China (No. 11905082) and the Fundamental Research Funds for the Central Universities (No.2662020GXPY002).

Conflicts of Interest: The authors declare no conflict of interest.

\section{References}

1. Ren, L.; Wang, Y.; Li, J.; Tong, J. Flexible unsmoothed cuticles of soil animals and their characteristics of reducing adhesion and resistance. Chin. Sci. Bull. 1998, 43, 166-169. [CrossRef]

2. Qaisrani, R.; Jian-qiao, L.; Khan, M.A.; Iram, R. Soil adhesion preventing mechanism of bionic bulldozing plates and mouldboard ploughs. Adv. Nat. Sci. 2010, 3, 100-107.

3. Tong, J.; Zhang, Q.Z.; Chen, D.H.; Chang, Y.; Wang, H.C. Effects of bionic geometric structure press rollers on reducing rolling resistance and adhesion against soil. Appl. Mech. Mat. 2013, 461, 63-72. [CrossRef]

4. Soni, P.; Salokhe, V.M. Influence of dimensions of UHMW-PE protuberances on sliding resistance and normal adhesion of bangkok clay soil to biomimetic plates. Bionic. Eng. 2006, 3, 63-71. [CrossRef]

5. Hurricks, P.L. Some metallurgical factors controlling the adhesive and abrasive wear resistance of steels. A review. Wear 1973, 26, 285-304. [CrossRef]

6. Hao, J.; Yang, Z.; Ma, L.; Zhao, J.; Liu, J. Fe-Cr-C-V plasma surfacing layer improving wear resistance and impact toughness of rotary blade. Trans. Chin. Soc. Agric. Eng. 2019, 35, 24-30.

7. Ren, L.Q.; Tong, J.; Li, J.Q.; Chen, B.C. Soil adhesion and biomimetics of soil-engaging components: A review. Agric. Eng. Res. 2001, 79, 239-263. [CrossRef]

8. Rosso, M.; Peter, I.; Gobber, F.S. Overview of heat treatment and surface engineering, influences of surface finishing on hot-work tool steel. Int. J. Microstruct. Mater. Prop. 2015, 10, 3-30. [CrossRef]

9. Marani, S.M.; Shahgholi, G.; Moinfar, A. Effect of nano coating materials on reduction of soil adhesion and external friction. Soil Tillage Res. 2019, 193, 42-49. [CrossRef]

10. Barzegar, M.; Hashemi, S.J.; Nazokdast, H.; Karimi, R. Evaluating the draft force and soil-tool adhesion of a UHMW-PE coated furrower. Soil Tillage Res. 2016, 163, 160-167. [CrossRef]

11. Li, J.W.; Tong, J.; Hu, B.; Ma, Y.H. Biomimetic functional surface of reducing soil adhesion on 65Mn steel. Adv. Mech. Eng. 2019, 11, 14. [CrossRef]

12. Jia, H.; Wang, W.; Wang, W.; Zheng, J.; Wang, Q.; Zhuang, J. Application of anti-adhesion structure based on earthworm motion characteristics. Soil Tillage Res. 2018, 178, 159-166. [CrossRef]

13. Cabezudo, N.; Sun, J.; Andi, B.; Ding, F.; Wang, D.; Chang, W.; Xu, B.B. Enhancement of surface wettability via micro-and nanostructures by single point diamond turning. Nanotech. Prec. Eng. 2019, 2, 8-14. [CrossRef]

14. Wos, S.; Koszela, W.; Pawlus, P. The effect of both surfaces textured on improvement of tribological properties of sliding elements. Tribol. Int. 2017, 113, 182-188. [CrossRef]

15. Gachot, C.; Rosenkranz, A.; Hsu, S.M.; Costa, H.L. A critical assessment of surface texturing for friction and wear improvement. Wear 2017, 372-373, 21-41. [CrossRef]

16. Rom, M.; Müller, S. A new model for textured surface lubrication based on a modified Reynolds equation including inertia effects. Tribol. Int. 2019, 133, 55-66. [CrossRef]

17. Zhang, D.; Gao, F.; Wei, X.; Liu, G.; Hua, M.; Li, P. Fabrication of textured composite surface and its tribological properties under starved lubrication and dry sliding conditions. Surf. Coat. Technol. 2018, 350, 313-332. [CrossRef] 
18. Xing, Y.; Deng, J.; Wu, Z.; Wu, F. High friction and low wear properties of laser-textured ceramic surface under dry friction. Opt. Laser Technol. 2017, 93, 24-32. [CrossRef]

19. Sadeghi, M.; Kharaziha, M.; Salimijazi, H.R. Role of micro-dimple array geometry on the biological and tribological performance of Ti6Al4V for biomedical applications. Surf. Coat. Technol. 2019, 362, 282-292. [CrossRef]

20. Liu, W.; Ni, H.; Wang, P.; Chen, H. Investigation on the tribological performance of micro-dimples textured surface combined with longitudinal or transverse vibration under hydrodynamic lubrication. Sci. Int. J. Mech. 2020, 174, 105474. [CrossRef]

21. Liu, W.; Ni, H.; Chen, H.; Wang, P. Numerical simulation and experimental investigation on tribological performance of micro-dimples textured surface under hydrodynamic lubrication. Int. J. Mech. Sci. 2019, 163, 105095. [CrossRef]

22. Guo, Z.; Xie, X.; Yuan, C.; Bai, X. Study on influence of micro convex textures on tribological performances of UHMWPE material under the water-lubricated conditions. Wear 2019, 426-427, 1327-1335. [CrossRef]

23. Lee, J.; Jung, S.Y.; Kumbhar, V.S.; Uhm, S.; Kim, H.J.; Lee, K. Formation of aluminum oxide nanostructures via anodization of Al3104 alloy and their wettability behavior for self-cleaning application. Catal. Today 2020. [CrossRef]

24. Wang, G.; Weng, D.; Chen, C.; Chen, L.; Wang, J. Influence of TiO2 nanostructure size and surface modification on surface wettability and bacterial adhesion. Coll. Interf. Sci. Commun. 2020, 34, 100220. [CrossRef]

25. Meng, R.; Deng, J.; Liu, Y.; Duan, R.; Zhang, G. Improving tribological performance of cemented carbides by combining laser surface texturing and W-S-C solid lubricant coating. Int. J. Refract. Meter. Hard Mat. 2018, 72, 163-171. [CrossRef]

26. Goshtasb, A.; Fielke, J.; Desbiolles, J. A review of soil/tool adhesion principles and approaches to reducing limitations of disc seeders. In Agricultural Technologies in a Changing Climate: The 2009 CIGR International Symposium of the Australian Society for Engineering in Agriculture; Engineers Australia: Darwin City, Australia, 2009.

27. Yuan, Y.; Lee, T.R. Contact angle and wetting properties. Surf. Sci. Techonl. 2013, 51, 3-34.

28. Wen, S. Principles of Tribology, Beijing; Tsinghua University Press: Beijing, China, 1990.

29. Li, D.; Yang, X.F.; Lu, C.Y.; Cheng, J.; Wang, S.R.; Wang, Y.J. Tribological characteristics of a cemented carbide friction surface with chevron pattern micro-texture based on different texture density. Tribol. Int. 2020, 142, 11.

30. Zhou, H.; Shi, X.; Yang, Z.; Wu, C.; Lu, G.; Xue, Y. Tribological property and frictional noise performance of titanium alloys with $\mathrm{Sn}-\mathrm{Ag}-\mathrm{Cu}$ and TiC filled into surface dimples. Tribol. Int. 2020, 144, 106-121. [CrossRef]

31. Nikolaeva, I.N. Stickiness of dark chestnut heavy loam and loam soils of the kustanai oblast under conditions of vertical tearing and tangential shear. Lipkost' Temno-Kashtanovykh Tyazhelosuglinistykh i Supeschanykh Pochv Kustanaiskoi Oblasti pri Vertikal'nom Otryve I Tangentsial'nom Sdvige. Available online: https://agris.fao.org/agris-search/search.do?recordID=US201300554312 (accessed on 12 June 2020).

32. Neal, M.S. Friction and adhesion between soil and rubber. J. Agri. Eng. Res. 1966, 11, 108-112. [CrossRef]

33. Ashokkumar, S.; Adler-Nissen, J.; Møller, P. Factors affecting the wettability of different surface 397 materials with vegetable oil at high temperatures and its relation to cleanability. Appl. Surf. Sci. 2012, 263, 86-94. [CrossRef]

34. Latthe, S.S.; Gurav, A.B.; Maruti, C.S.; Vhatkar, R.S. Recent progress in preparation of superhydrophobic surfaces: A review. J. Surf. Eng. Mat. Adv. Techonl. 2012, 2, 76-94.

35. Chen, L.; Wang, S.Y.; Xiang, X.; Tao, W.Q. Mechanism of surface nanostructure changing wettability: A molecular dynamics simulation. Comput. Mater. Sci. 2020, 171, 109223. [CrossRef]

36. Qiu, Y.; Khonsari, M.M. Experimental investigation of tribological performance of laser textured stainless steel rings. Tribol. Int. 2011, 44, 635-644. [CrossRef]

37. Xing, Y.; Deng, J.; Feng, X.; Yu, S. Effect of laser surface texturing on Si3N4/TiC ceramic sliding against steel under dry friction. Mater. Des. 2013, 52, 234-245. [CrossRef]

38. Flegler, F.; Neuhäuser, S.; Groche, P. Influence of sheet metal texture on the adhesive wear and friction behaviour of EN AW-5083 aluminum under dry and starved lubrication. Tribol. Int. 2019, 141, 105956. [CrossRef]

39. Lepage, J.; Brion, J.M. Paper VIII (iv) role of wear debris in the environmental effect in tribology. Tribology 1992, 21, 369-374.

40. Ren, L. Soil Adhesion Mechanics; Mechanical Industry Press: Beijing, China, 2011.

41. Yang, J.; Liu, Z.; Cheng, Q.; Liu, X.; Deng, T. The effect of wear on the frictional vibration suppression of water-lubricated rubber slat with/without surface texture. Wear 2019, 426-427, 1304-1317. [CrossRef] 
42. Li, Z.Y.; Yang, W.J.; Wu, Y.P.; Wu, S.B.; Cai, Z.B. Role of humidity in reducing the friction of graphene layers on textured surfaces. Appl. Surf. Sci. 2017, 403, 362-370. [CrossRef]

43. Wang, X.; Adachi, K.; Otsuka, K.; Kato, K. Optimization of the surface texture for silicon carbide sliding in water. Appl. Surf. Sci. 2006, 253, 1282-1286. [CrossRef]

(C) 2020 by the authors. Licensee MDPI, Basel, Switzerland. This article is an open access article distributed under the terms and conditions of the Creative Commons Attribution (CC BY) license (http://creativecommons.org/licenses/by/4.0/). 